\title{
Model of Expatriates' Job Performance Based on Cross-Cultural Adjustment to Work Stress and Work Adaptation
}

\author{
Yueh-Shian Lee \\ Department of Business Administration, Ming Dao University, Taiwan \\ Email: yslee@mdu.edu.tw
}

How to cite this paper: Lee, Y.-S. (2021). Model of Expatriates' Job Performance Based on Cross-Cultural Adjustment to Work Stress and Work Adaptation. Theoretical Economics Letters, 11, 540-557.

https://doi.org/10.4236/tel.2021.113036

Received: April 27, 2021

Accepted: June 21, 2021

Published: June 24, 2021

Copyright $\odot 2021$ by author(s) and Scientific Research Publishing Inc. This work is licensed under the Creative Commons Attribution International License (CC BY 4.0).

http://creativecommons.org/licenses/by/4.0/

(c) (i) Open Access

\begin{abstract}
The study aims to determine factors affecting the job performance relating to cross-cultural adjustment as it affects work stress and work adaptation. For this study, the research framework was based on cross-cultural flexibility associated with work adaptation and work stress on job performance among expatriates. The research was conducted on a sample of 396 expatriates working in the hospitality industry in Taiwan. Structural equation modeling was utilized in this study. The obtained results confirmed the impact of cross-cultural adjustment on work stress, the negative impact of work stress on job performance; and also, the positive impact of cross-cultural adjustment on work adaptation, and work adaptation on job performance. The results show that the challenges faced by expatriates are derived from work adaption, work stress, and cultural differences. Expatriates who can adapt to the different cultures of foreign countries have higher work participation. It has also been found that a significant correlation exists between cross-cultural adjustments on work pressure. Higher work stress translates into relatively lower job performance.
\end{abstract}

\section{Keywords}

Expatriates, Cross-Cultural Adjustment, Work Stress, Work Adaptation, Job Performance

\section{Introduction}

With increasing globalization, companies are entering an energetic world of global business. Sending employees to work abroad is becoming normal practice. However, there are complex challenges in managing expatriate employees. Sending expatriate employees abroad includes a full host of issues, with the expense 
of expatriate failure looming large (Chen \& Shaffer, 2018). This research investigates various approaches to assist expatriates in integrating into Taiwan's hospitality industry and enhancing their job performance. It then turns to the management of expatriate employees, including exploring their work stress, work adaptation and job performance. Finally, this paper describes the challenges occurring in the management of expatriate employees, and the impact of crosscultural adjustment on international human resources management. The purpose of managing expatriate employees is to boost cross-cultural flexibility as an important element that smooths their work stress and work adaptation; it is also a component related to the job performance of a company in a hit or miss environment (Wang et al., 2020).

Consideration of cross-cultural adjustment caused by differences in life and social culture and their influence on an expatriate employee's work stress (Sterle et al., 2018; Strong, 2005), with an increasing number of expatriate employees, expatriation expenses for companies become higher. Expatriates result in resignation because of losing their self-esteem and having negative attitudes. Expatriate management will be an essential consideration in future human resource management and also a significant challenge. Companies should emphasize the success of expatriated employees and supply the necessary support for their career abroad (Vijayakumar \& Cunningham, 2016). Furthermore, assistance of expatriate employees during times of individual emergency, also with providing tools for relief of their anxiety is essential. Studies concerning expatriate management began as early as the 1970s; however, this research has only begun more recently in Taiwan. Thus, a Taiwanese research project on expatriate employee management has not yet been formed. In summary, from the perspective of balancing the work stress, work adaptation and job performance after cross-cultural adjustment, this study was conducted via questionnaires to investigate the implication of these factors on expatriate job performance. This study makes several contributions to expatriate management and cross-cultural flexibility (McNulty et al., 2017), and presents a brand-new model of cross-cultural adjustment as it affects how job stress and job adaptation relate to job performance.

\section{Literature Review}

\subsection{Research Background}

The management of expatriate employees is also perceived as the management of the relationship between host-country managers and expatiate employees to produce the best value for expatriates functioning. In developing an appropriate model of expatriate management, it is important to emphasize the requirement for integration within cross-cultural adjustment. The development of an expatriate management model across differing cultures will also be a gradual process. The literature contains numerous studies that try to demonstrate cross-cultural adjustment for expatriates cooperated to realize effects and affected the job per- 
formance. Well work adaption requires achieving a level of cultural flexibility that permits expatriate to achieve their best performance (Caligiuri, Baytalskaya, \& Lazarova, 2016). The following issues should be considered: low job performance as associated with high work stress; and consequences of labor adaption as related to efficiency and high job performance. An objective should be to decrease work stress because high work-stressed expatriates are less competitive and, therefore, deliver a lower level of job performance. However, to achieve a high level of job performance, an extra level of internal tension is required in the workplace with bottom level of labor stress. Marcenes and Sheiham (1992) stated that employment stress is related to the most important risk which implies that an employee's lower tolerance stress and greater tendency toward excessive caution are related to the danger of disrupting job performance, increasing costs, and missing out on the chance to cooperate with others and achieve higher levels of performance; hence, it is important to that human resource are provided to support expatriates with latent disabilities in workplace (Ziervogel, 2019).

Fundamentally, expatriate management should be built around achieving cross-culture adjustment while minimizing the disorientation among expatriates (Linder, 2015). Expatriates are essential for collaboration (Jun, Gentry \& Hyun, 2001; Trembath, 2016). According to Amiruddin's study (2019), issue such as culture, language, safety and security, and family life are typical for cooperative relationships in an expatriate. Spong and Kamau (2012) emphasized cross-cultural adjustment, work stress, work adaptation as factors which influencing job performance (Morrow, 2013).

Factors contributing to cooperation in an expatriate are indicated as determinants of the employee's relationship affecting work stress and work adaptation and are noted because the determinants of the expatriate's job performance as they affect the strength of cross-cultural adjustment (Bierwiaczonek \& Waldzus, 2016; Murray, 2008).

Initially, work stress is primarily linked to the assessment of an expatriate's disorientation, their competences yet because the expected benefits of cooperation (Smith \& Greenfields, 2012). Due to the shortage of previous experience, the central role in facilitating culture adjustment is given to management's continued support of, and assistance programs for, expatriates by Levine \& Levine (2014); however, Briner, Harris \& Daniels (2004) demonstrated that expatriates find local support more beneficial than long-distance contact with the human resource department in their home-country office. Local support groups can better understand and help with advice or practical assistance on a wide range of issues that can help settle in at their new location (Oltra et al., 2013; Wilson et al, 2017).

\subsection{Cross-Cultural Adjustment}

Cross-cultural adjustment refers to the method of adapting to life in the host culture. Fee (2020) described the methods of adjustment including acculturation, disorientation, and cross-cultural adaptation. Durand et al. (2004) described 
cross-cultural adjustment as a continuum of adjusting to changing conditions, including the method of re-entry to the employee's native culture. This process examines the adjustment to what is considered acceptable behavior within the new culture and customs with which an expatriate interact. The individual can function in the new cultural environment. Faulconbridge (2008) demonstrated that expatriates begin the cross-cultural process with optimism, followed by levels of dissatisfaction, and at last ending in a recovery state. Kirkegaard and Brinkmann (2015) found that the majority of expatriate establish patterns for his or her cross-cultural adjustment looking at several conditions including: previous international experience, language acquisition, and cross-cultural training (Ford et al., 2016; Rozaimie, 2018). The concept of disorientation has been extended to include the process of emotional and condition of a private when individuals reenter their home country from another culture (Hack-Polay, 2020). An analysis of the impact of work stress and work adaptation on expatriate has been offered by Tharenou (2013). The authors demonstrated the impact of both constructs on expatriates' job performance and also their willingness to take on a foreign position in the future.

\subsection{Work Stress}

Cavallo et al. (2005) divided work stress into interpersonal relationship stress, task relationship stress, organizational relationship stress, and physical and mental relationship stress. The literature largely emphasizes the influence of expatriate's job stress on cross culture adjustment (Wang, 2006). According to Karakaş \& Tezcan (2019) measurements of work stress as applied within the study are: interpersonal relationship, task relationship, organizational relationship, and physical relationship. Interpersonal relationship is stipulated as the character of the local people, work characters, and the poor relationship among organization's team member due to conflict. Task relationship is demonstrated through large workloads, unclear tasks, and task conflicts (Lu et al., 2011). Organizational relationship is expounded to the organizational pattern, management model, and organizational support system. Physical relationship includes way of life, inconvenient transportation, and unfair treatment. Work stress increase the chance of expatriate's poor behavior and diminishes the necessity for an in-depth contract or other mechanisms accustomed secure and monitor the execution of transactions. Kirkegaard \& Brinkmann (2015) asserted that work stress was a unique reaction to the interaction between the attitudes toward strong workplace-related conflicts. Weinberg (2015) reported that work stress can have a negative physiological and psychological influence on a worker when his or her individual capability does not live up to the corresponding work expectation (Shin, Morgeson \& Campion, 2007).

\subsection{Work Adaptation}

Work adaptation is indicated as the main precursor of cooperation as well as the 
main element contributing to long-term job performance (Braman et al., 2010; Snowden, 2011). Work adaptation determining that cooperative strategy can be successful and become the dominant strategy, cooperation should be mentioned (Brunner, 2016; Gvozdeva \& Gvozdeva, 2006; Harvey \& Novicevic, 2001). Management of expatriates differs from the typical employment relationship of native workers that determines when a person works or performs services under certain conditions in return for remuneration (Roniger, 2016; Ruddick, 2005). There may be cultural differences in the application of social security, law provisions addressed to employees, and extent of employers' rights and obligations towards their workers (Loring et al., 2016; Orrange, 2003).

Work adaptation occurs when expatriates change or adjust their own culture processes to improve cooperation with the host culture (Khammar et al, 2017; Pritchard et al., 2019). Work adaptation is a consequence of behavior adjustment and can be expressed in the implementation of specific preparation aimed at improving cooperation (Byrne \& Kirwan, 2019; Lamond et al., 2004). Work adaptation is an essential element of cooperation. Cooperation either usually involves good work adaptation, it is possible to explain or predict the level of expatriate job performance (Devaraj \& Jiang, 2019; Nilforooshan, 2020). The presence of good work adaptation between entities reduces uncertainty and the risk of actions taken (Byrne \& Kirwan, 2019). Good work adaptation allows a more flexible response to changes in the new environment (Caligiuri, Baytalskaya, \& Lazarova, 2016; Pullen Sansfaçon et al., 2014). Based on previous research results, this research proposes the following research hypotheses:

$\mathrm{H1}$ : Cross-cultural adjustment has significant impact on work stress of expatriates.

H2: Cross-cultural adjustment has a significant impact on work adaptation of expatriates.

\subsection{Job Performance}

Job performance can also be increased by undertaking activities designed to strengthen job adaptation. According to Kleinschmidt and Jaeger (2016) there is poor job performance in the absence of a good level of work adaptation. Hence, the following statement: Job performance refers to the extent to which an employee fulfills his or her prescribed work role expectation. To cope with global environmental uncertainly, an international company needs expatriate workers who exceed their work abilities by promoting and realizing new situations for change.

Gray-Stanley et al. (2010) defined work stress as the spiritual fatigue caused by being slowly exposed to job stress over time; when the employee felt exhausted, such exhaustion at work would result in the lack of work enthusiasm, high frustration, nervousness, and affect job performance. Schieman and Young (2010) revealed that most work stressors of expatriates, with the exception of organization, were positive, reflecting that the formation of individual work stress can 
have positive effects on job performance. Kanji and Chopra (2009) concluded that higher work stress was correlated with lower job performance. Schieman, \& Young (2010) found contradictory tasks, and burdensomely heavy tasks to be the major factors in creating work stress, resulting in spiritual fatigue, loss of one's identity, and depression of mood. Work stress was correlated with a heavy workload and task contradictions, and an overly heavy workload was shown to reduce job performance. Soumyashree et al. (2018) revealed that work stress of an expatriate, except for organization, tended to be negative, reflecting that the formation of individual work stress can have negative effects on job performance. Nabitz et al (2009) concluded that higher work stress was correlated with lower job performance. Work stress was correlated with a heavy workload and task contradictions, and heavy workload was shown to reduce job performance

Dollard, Osborne and Manning (2013) indicated that job performance refers to the completion of work with efficiency and effectiveness. Gandhi and French (2004) stated that job performance refers to the evaluated work behavior and work results of employees, which are beneficial to the achievement of corporate goals. The contributing part is often used in the research and evaluation of human resources in corporate management. However, the authors demonstrated that the level of job performance depended on task performance and contextual performance, which are separately measured. Task performance can be reflected in the aspects of task quantity, task quality, and completion efficiency, while the contextual performance can be measured by the research results of Robertson et al. (2001). Severn (2014) arrived at similar conclusions. The authors confirmed the impact of these factors on job performance and proved that the level of job performance determined the level of work adaptation in the expatriates.

In this context, the following propositions regarding job performance were established:

H3: Work stress has a significant negative impact positive on job performance of expatriates.

H4: Work adaptation has a significant positive impact positive on job performance of expatriates.

\section{Conceptual Model}

The research framework for this study is based on the notion that expatriate job performance requires cross culture adjustment, and job adaption and job stress are critical elements which influence to job performance among expatriate employees. The theoretical expectations and findings from the literature review enabled the indication of a hypothetical model (Figure 1).

This study proposed a model of cross-cultural adjustment springing from differences in life and culture which influence an expatriate's work stress and work adaptation, and consequently on work performance. Cross-cultural adjustment refers to the interaction among people in difference countries. For example, previous interactions between people have been communicated through language. 


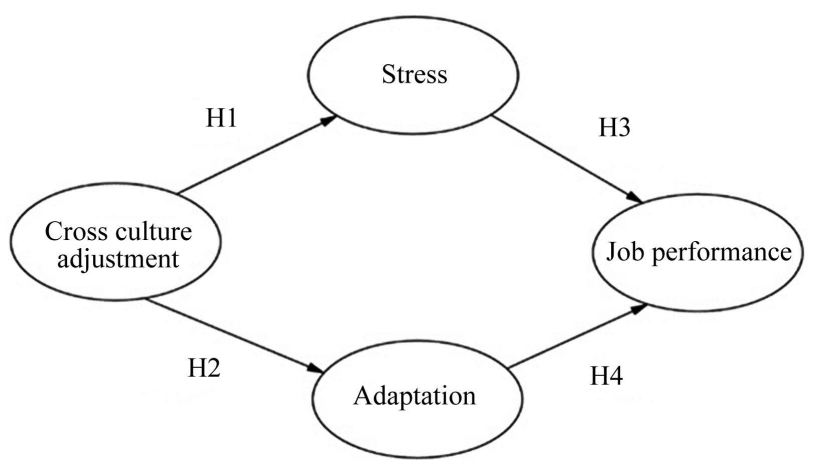

Figure 1. Hypothetical model.

Different countries use differing means of cultural expression. Effective cultivation of foreigners' cultural adaptation includes three aspects: self-adjustment, cognitive feeling, and cultural toughness.

The literature shows that expatriate's work stress was primarily due to interpersonal relationship, task relationship, organizational relationship, and physical relationship.

Additionally, this study shows that expatriate work adaptation refers to a worker's satisfaction and acceptance of current work. Wok adaptation can be divided into two dimensions, such as the enthusiastic participation and individual initiative to improve one's work in comparison with others. Job performance can be expressed as the implementation of specific investments aimed at improving contributing to task success (Presbitero, 2017). The construct named cross-cultural adjustment was introduced as a precursor of work stress and work adaptation. Employees who have succeeded at home may not repeat that success abroad. Dispatched managers must choose expatriates who have both the necessary skills and also have indicated that they would be likely to live comfortably in different cultures.

The article provides definitions of the model related to expatriate's job performance then, it introduces the theoretical framework with hypotheses between constructs and describes the research methodology and outcomes of empirical investigation. Next, the article discusses the sampling and statistical methods used in the study to test the hypotheses and offers a discussion of the results and conclusions.

\section{Research Methodology}

\subsection{Structural Equation Modelling}

Structural equation modelling (SEM) allows for building a model using latent variables that are difficult to measure directly by a single item, e.g. work stress, work adaption, and job performance. Latent variables are measured indirectly through observable variables, e.g. questionnaire answers. SEM combines regression analysis with confirmatory factor analysis and allows testing hypotheses with a high potential for the complexity of relationships between variables. The 
most significant feature of SEM is the ability to estimate direct and indirect relationships among variables. The structural model shows dependencies between exogenous variables and endogenous variables. Another feature includes the observable and the latent variables into the identical analysis. The hypothesized structural model is presented as path diagrams (Figure 2) and as a group of Equations (1)-(15).

$$
\begin{gathered}
\mathrm{F} 2=\mathrm{W} 1 \times \mathrm{F} 1+\mathrm{e} 13 \\
\mathrm{~F} 3=\mathrm{W} 2 \times \mathrm{F} 1+\mathrm{e} 14 \\
\mathrm{~F} 4=\mathrm{W} 3 \times \mathrm{F} 3+\mathrm{W} 4 \times \mathrm{F} 2+\mathrm{e} 15 \\
\mathrm{X} 1=\mathrm{W} 5 \times \mathrm{F} 1+\mathrm{e} 1 \\
\mathrm{X} 2=\mathrm{W} 6 \times \mathrm{F} 1+\mathrm{e} 2 \\
\mathrm{X} 3=\mathrm{W} 7 \times \mathrm{F} 1+\mathrm{e} 3 \\
\mathrm{X} 4=\mathrm{W} 8 \times \mathrm{F} 1+\mathrm{e} 4 \\
\mathrm{X} 5=\mathrm{W} 9 \times \mathrm{F} 2+\mathrm{e} 5 \\
\mathrm{X} 6=\mathrm{W} 10 \times \mathrm{F} 2+\mathrm{e} 6 \\
\mathrm{X} 7=\mathrm{W} 11 \times \mathrm{F} 2+\mathrm{e} 7 \\
\mathrm{X} 8=\mathrm{W} 12 \times \mathrm{F} 2+\mathrm{e} 8 \\
\mathrm{X} 9=\mathrm{W} 13 \times \mathrm{F} 3+\mathrm{e} 9 \\
\mathrm{X} 10=\mathrm{W} 14 \times \mathrm{F} 3+\mathrm{e} 10 \\
\mathrm{X} 11=\mathrm{W} 15 \times \mathrm{F} 4+\mathrm{e} 11 \\
\mathrm{X} 12=\mathrm{W} 16 \times \mathrm{F} 4+\mathrm{e} 12
\end{gathered}
$$

The first step of the model present one exogenous latent variable, F1, and two endogenous latent variable, F2 and F3, where regression coefficients $\mathrm{W} 1$ and $\mathrm{W} 2$ determine the effect of exogenous variables F1 on endogenous variable F2 and F3, respectively. The second step of the model presents two exogenous latent

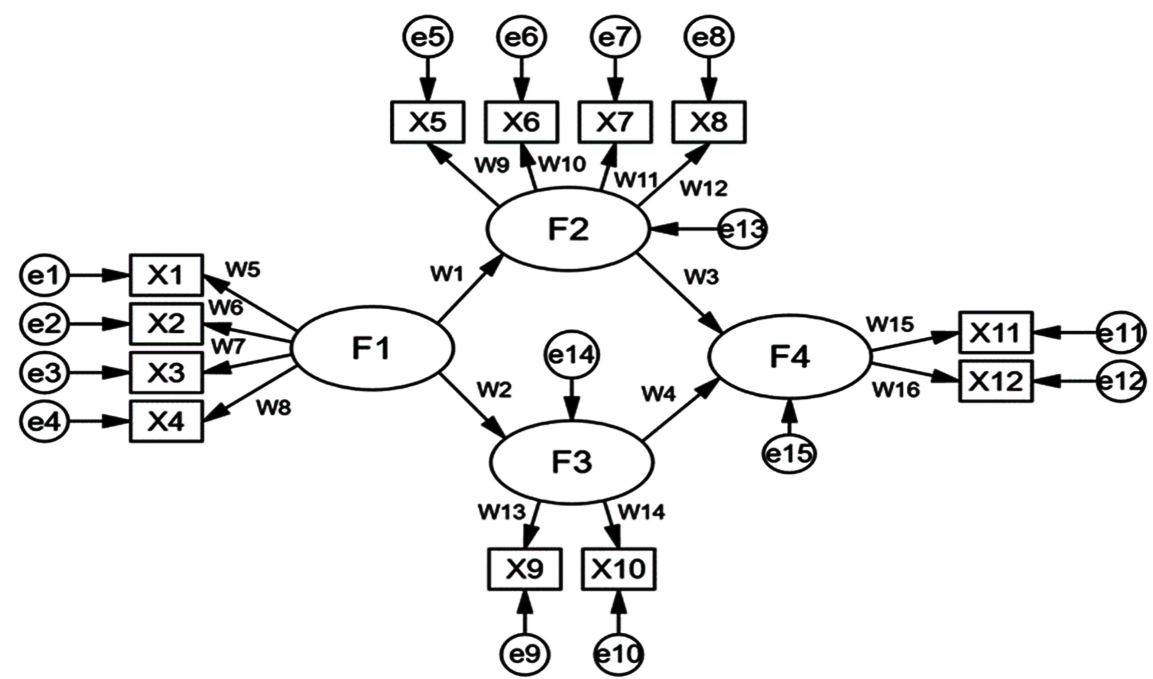

Figure 2. Hypothesize structural model. 
variables, F2 and F3, and an endogenous latent variable, F4, where regression coefficients W3 and W4 determine the effect of exogenous variables F2 and F3 on endogenous variable F4. The variables F1, F2, F3 and F4 are measured by observable variables $\mathrm{X} 1, \mathrm{X} 2, \mathrm{X} 3, \mathrm{X} 4$, and $\mathrm{X} 5, \mathrm{X} 6, \mathrm{X} 7, \mathrm{X} 8$ as well as $\mathrm{X} 9, \mathrm{X} 10$, and $\mathrm{X} 11, \mathrm{X} 12$ respectively. Parameters $\mathrm{W} 1$ to $\mathrm{W} 16$ are the factor loadings of a specific variable with the corresponding variables. The variables e1 to e16 mean measurement errors of variables.

\subsection{Data Collection}

A pilot test was conducted before sending the questionnaire. The head of the human resources department and three human resources experts and scholars reviewed the questionnaire to confirm whether the question was clear and revised the unclear items. Ensure the validity and reliability of the questionnaire. In response to the hospitality industry, 550 questionnaires were distributed to Indonesian workers in the Taiwanese hospitality industry, and 460 questionnaires were collected. The response rate of all questionnaires was $84 \%$. To ensure that each questionnaire provide valid survey results, 64 invalid questionnaires were discarded, while 396 valid questionnaires were preserved. The final response rate of valid questionnaire was $72 \%$, which met the requirements for validity.

The research constructs included cross-cultural adjustment; work stress, work adaptation, and job performance, comprising the total of 12 indicators (observable variables) (see Table 1). The questionnaire was compiled by the authors

Table 1. Confirmatory factor analysis results.

\begin{tabular}{|c|c|c|c|}
\hline Construct & & Item & Standardized \\
\hline \multirow{4}{*}{$\begin{array}{l}\text { Cross culture } \\
\text { adjustment }\end{array}$} & $\mathrm{CC} 1$ & $\begin{array}{l}\text { I like to communicate with people from different } \\
\text { cultural backgrounds }\end{array}$ & 0.714 \\
\hline & CC2 & $\begin{array}{l}\text { I can properly resolve conflicts with people from } \\
\text { different cultural backgrounds }\end{array}$ & 0.705 \\
\hline & CC3 & $\begin{array}{l}\text { When people from different cultural backgrounds need } \\
\text { help, I will make suggestions in a way that they can accept }\end{array}$ & 0.733 \\
\hline & $\mathrm{CC} 4$ & $\begin{array}{l}\text { In different cultural backgrounds, I can tolerate higher } \\
\text { uncertainty }\end{array}$ & 0.728 \\
\hline \multirow{4}{*}{$\begin{array}{l}\text { Work } \\
\text { stress }\end{array}$} & WS1 & My job is prone to affect health directly & 0.830 \\
\hline & WS2 & I am working under quite a stress. & 0.800 \\
\hline & WS3 & I feel irritable because of my work & 0.844 \\
\hline & WS4 & I feel nervous before the meetings held in my company & 0.804 \\
\hline \multirow{2}{*}{$\begin{array}{l}\text { Work } \\
\text { adaptation }\end{array}$} & $\mathrm{AD} 1$ & At work, I can be self-disciplined and self-restrained. & 0.475 \\
\hline & $\mathrm{AD} 2$ & $\begin{array}{l}\text { I will seek the cooperation of colleagues and relevant } \\
\text { departments to complete the work. }\end{array}$ & 0.670 \\
\hline Job & JP1 & I can accomplish tasks & 0.842 \\
\hline performance & JP2 & I uphold the highest professional standards & 0.751 \\
\hline
\end{tabular}


based on the literature review. Work stress was measured by four items relating to physical and mental health. Work adaptation was measured by two items relating to self-disciplined and cooperation with colleagues. Job performance was measured by two items relating to the ability to accomplish tasks and achieve a high professional standard. A five-level Likert scale was used in the questionnaire to evaluate each indicator from "strongly disagree" (1) to "strongly agree" (5).

\subsection{Research Process Design}

The article provides definitions of the major theoretical constructs related to work stress, work adaption, and job performance based on cross-cultural adjustment. Then, this study describes the theoretical framework with hypotheses between construct, research methodology and outcomes of empirical investigation. In the study structural equation modeling using the maximum likelihood method was used. The confirmatory factor analysis and the structural model were used. The data analysis was based on the IBM SPSS Statistics 25.0 software with an additional module (AMOS) used for structural equation modelling.

\section{Results}

In the first step, the confirmatory factor analysis (CFA) was conducted. CFA is used after the development of a scale to test whether specific items fall under the various dimensions of theoretical expectations. In this study, the measurement model exhibited at insignificant levels $(p>0.05)$. Also, the goodness-of -fit (GOF) indices were accepted by the measurement model exhibited at insignificant levels, (GOF) indices were accepted by the CMIN/DF $=1.312(<2)$; RMSEA $=0.028(<0.08)$, and GFI $=0.975(>0.9)$ (see Figure 3$)$.

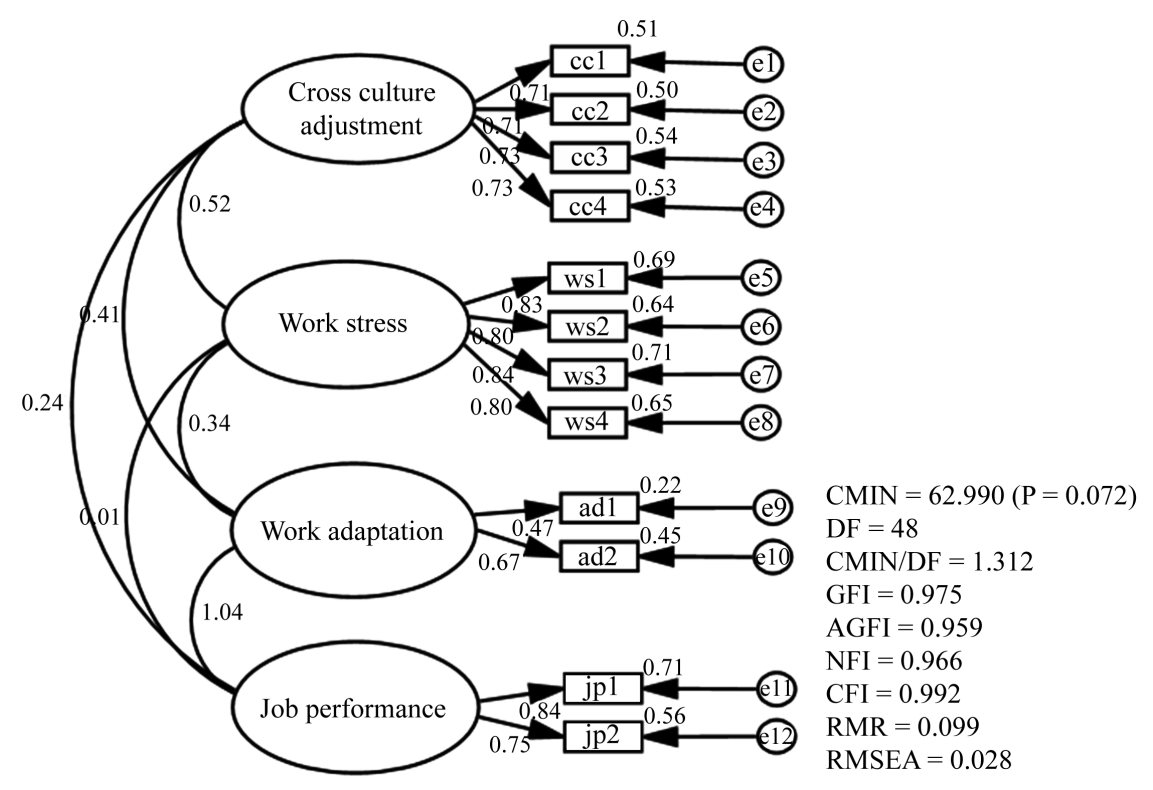

Figure 3. Model of confirmatory factor analysis. 
Furthermore, all factors were of a significant level $(p>0.001)$. The results of factor loadings on construct of cross culture adjustment, work stress, and job performance, the standardized regression weights linking a specific observable indicator with a latent variable were higher than 0.71 were categorized as excellent; factor loadings on construct of work adaptation are 0.475 and $0.670(>0.45)$, and were categorized as sufficient (Hair et al, 2010) (see Table 1). Therefore, all indicators were included form the measurement model; a compound of four latent variables and 12 observable variables.

In addition, the results of the four major constructs indicated reliable indictors of composite reliability (CR) above 0.45 (from 0.497 to 0.891 ) and average variance extract (AVE) above 0.5 (from 0.0519 to 0.672 ), which satisfied the accepted requirements (see Table 2). Overall, these analyses support the reliability and validity of the constructs.

The structure model was specified based on the conceptual model (Figure 1). The result of the estimation of the structural model was that four paths proved to be statistically significant (see Table 3). The result supported the hypothetical model. The obtained results confirmed the positive impact of cross-cultural adjustment on work stress (W1 (CCA, WS) $=0.53$; $p<0.001)$, cross-cultural adjustment on work adaptation (W2 $(\mathrm{CCA}, \mathrm{WP})=0.37 ; p<0.001)$, work adaptation on job performance (W3 (WA, JP) $=-0.27 ; p<0.001$ ), work stress on job performance cooperation (W4 (WS, JP) $=1.07 ; p<0.001$ ), providing support for the hypotheses $\mathrm{H} 1, \mathrm{H} 2, \mathrm{H} 3$, and $\mathrm{H} 4$.

In general, the conceptual model in this study relies on theoretical bases, the adequacy of indices of the CFA, and the satisfied GOF indices (see Figure 2). The paths are tested in the conceptual framework. Table 3 presents the results of the paths in the model, including the standardized coefficient, standard error,

Table 2. Confirmatory factor analysis results.

\begin{tabular}{|c|c|c|c|c|c|c|}
\hline \multicolumn{2}{|c|}{ Constructs } & \multirow{2}{*}{$\begin{array}{c}\text { Standardized loading }(\mathrm{W}) \\
0.714\end{array}$} & \multirow[t]{2}{*}{ Mean } & \multirow[t]{2}{*}{ AVE } & \multirow[t]{2}{*}{$\mathrm{CR}$} & \multirow[t]{2}{*}{$\alpha$} \\
\hline \multirow{4}{*}{$\begin{array}{l}\text { Cross culture } \\
\text { adjustment }\end{array}$} & CC1 & & & & & \\
\hline & $\mathrm{CC} 2$ & 0.705 & \multirow{3}{*}{4.030} & \multirow{3}{*}{0.519} & \multirow{3}{*}{0.812} & \multirow{3}{*}{0.811} \\
\hline & CC3 & 0.733 & & & & \\
\hline & $\mathrm{CC} 4$ & 0.728 & & & & \\
\hline \multirow{4}{*}{$\begin{array}{l}\text { Work } \\
\text { stress }\end{array}$} & WS1 & 0.830 & \multirow{4}{*}{3.916} & \multirow{4}{*}{0.672} & \multirow{4}{*}{0.891} & \multirow{4}{*}{0.891} \\
\hline & WS2 & 0.800 & & & & \\
\hline & WS3 & 0.844 & & & & \\
\hline & WS4 & 0.804 & & & & \\
\hline \multirow{2}{*}{$\begin{array}{c}\text { Work } \\
\text { adaptation }\end{array}$} & WA1 & 0.474 & \multirow{2}{*}{3.835} & \multirow{2}{*}{0.637} & \multirow{2}{*}{0.497} & \multirow{2}{*}{0.482} \\
\hline & WA2 & 0.670 & & & & \\
\hline \multirow{2}{*}{$\begin{array}{c}\text { Job } \\
\text { performance }\end{array}$} & JP1 & 0.842 & \multirow{2}{*}{3.736} & \multirow{2}{*}{0.636} & \multirow{2}{*}{0.777} & \multirow{2}{*}{0.775} \\
\hline & JP2 & 0.751 & & & & \\
\hline
\end{tabular}


Table 3. Results of the structural model.

\begin{tabular}{|c|c|c|c|c|c|c|}
\hline Hypo-theses & Path & $\begin{array}{l}\text { Standardized } \\
\text { path } \\
\text { coefficient }(\mathrm{W})\end{array}$ & $\begin{array}{c}\text { Standardized } \\
\text { error } \\
\text { (S. E.) }\end{array}$ & $\begin{array}{l}\text { Critical } \\
\text { Ratio } \\
\text { (CR) }\end{array}$ & $p$-value & Result \\
\hline H1 & $\begin{array}{l}\text { Cross-cultural } \\
\text { adjustment } \\
\rightarrow \text { work stress }\end{array}$ & 0.53 & 0.06 & 8.366 & 0.00 & Supported \\
\hline $\mathrm{H} 2$ & $\begin{array}{c}\text { Cross-cultural } \\
\text { adjustment } \\
\rightarrow \text { Work adaptation }\end{array}$ & 0.37 & 0.060 & 4.544 & 0.00 & Supported \\
\hline $\mathrm{H} 3$ & $\begin{array}{c}\text { Work stress } \\
\rightarrow \text { Job performance }\end{array}$ & -0.27 & 0.61 & 4.559 & 0.00 & Supported \\
\hline $\mathrm{H} 4$ & $\begin{array}{l}\text { Work adaptation } \\
\rightarrow \text { Job performance }\end{array}$ & 1.07 & 0.276 & 7.488 & 0.00 & Supported \\
\hline
\end{tabular}

critical ration, and p-value. As shown in Table 3, the four hypotheses are found to be significant and supported the previous research.

First, cross-cultural adjustment is significantly and positively related to work stress ( $\mathrm{W}=0.53, p<0.001$ ). This finding supports the argument of Rafiq et al. (2019), who claimed the essentiality of classification among the four categories of cross-cultural adjustment. Raitt (2012) also found a positive effect of crosscultural adjustment on work stress. Second, the findings support the positive influence of cross-cultural adjustment on work adaptation. Customer satisfaction $(\mathrm{W}=0.37, p<0.001)$. According to previous research, the relationship between cross-cultural adjustment and work adaption should be positive. Third, work stress has a negativities influence on job performance $(\beta=-0.276, p<0.001)$. Based on the view of Qin \& Baruch (2010), there is a negative relationship between these two constructs. Fourth, work adaption manifests a significant effect on job performance $(\mathrm{W}=1.07, p<0.001)$.

In the conceptual model (see Figure 4), structural equation modeling (SEM) is conducted to test the model fit indices. In the conceptual model, the ratio of the chi-square to the degree of freedom (CMIN/DF) is 0.985 , which can be considered acceptable. The indices obsolete fit on RMR, RMESEA, GFI, and AGFI are $0.0049,0.071,0.947$, and 0.917 , respectively. These values satisfy the RMR $(<0.005)$, RMSEA (0.08), CFI $(>0.90)$, and AGFI $(>0.9)$ (Hair et al., 2010). The above test of goodness-of-fit indices describes the conceptual model in this study.

This study confirmed that: work stress and work adaptation are antecedent of job performance as was expressed by Sterle et al. (2018) and Thoms et al. (2002). In addition, cross-cultural adjustment influence work stress and work adaptation as was formulated by Vermeulen et al. (2019).

The study also demonstrated the positive impact of cross-cultural adjustment on work stress and work adaptation. When selection expatriate, the characteristics of the host country must be considered, and the personal cross-cultural 


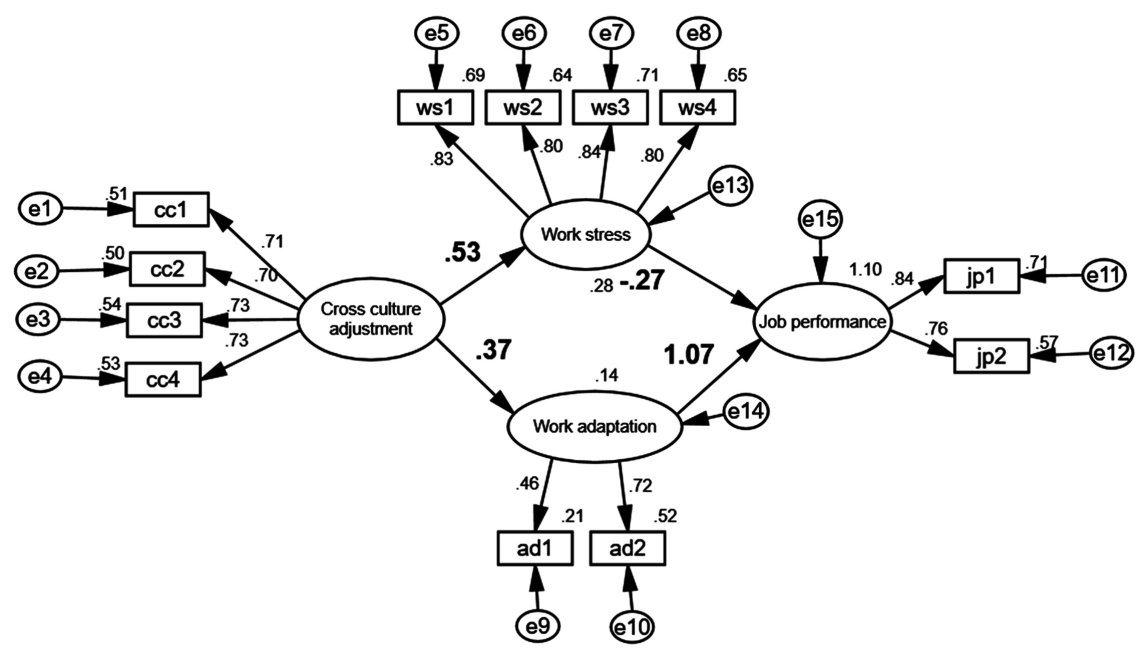

Figure 4. Structural equation modeling.

adaptability of the potential expatriate must be evaluated. Selection for a combination of cross-cultural competence and personal adaptability ensure that expatriates can quickly adjust to the culture of the host country, thereby improving work performance (Fee, 2020).

\section{Conclusion}

The research aims to find that the factors affecting job performance include two elements. The first element is the influence of cross-cultural adjustment on work adaptation and work pressure. The second element is the impact of work adaptation and work pressure on job performance. This study established a model based on theoretical foundations, and through factor analysis and structural equation analysis, it was found that cross-cultural adjustment has a demonstrable effect on work adaption and work stress. Work adaptation is positively and significantly correlated with job performance, and work stress is negatively correlated with job performance. Therefore, in order to improve the performance of expatriates, organizations need to pay attention to the cross-cultural adaptation of employees.

This study was based on a questionnaire survey of foreign employees in the Taiwanese hospitality industry, most of whom are subordinate-level employees. Therefore, the requirements for interpersonal communication in the workplace are relatively low at work. For high-level positions that require frequent communication with customers and supervisors, in terms of the cultural background of the employees, the capability of expatriates will be more diverse. Therefore, further research is needed in this area.

\section{Conflicts of Interest}

The author declares no conflicts of interest regarding the publication of this paper. 


\section{References}

Amiruddin, A. (2019). Mediating Effect of Work Stress on the Influence of Time Pressure, Work-Family Conflict and Role Ambiguity on Audit Quality Reduction Behavior. International Journal of Law and Management, 61, 434-454. https://doi.org/10.1108/IJLMA-09-2017-0223

Bierwiaczonek, K., \& Waldzus, S. (2016). Socio-Cultural Factors as Antecedents of Cross-Cultural Adaptation in Expatriates, International Students, and Migrants: A Review. Journal of Cross-Cultural Psychology, 47, 767-817. https://doi.org/10.1177\%2F0022022116644526

Braman, L. M., Suarez, P., \& Aalst, M., K. (2010). Climate Change Adaptation: Integrating Climate Science into Humanitarian Work. International Review of the Red Cross, 92, 693-712. https://doi.org/10.1017/S1816383110000561

Briner, R. B., Harris, C., \& Daniels, K. (2004). How Do Work Stress and Coping Work? Toward a Fundamental Theoretical Reappraisal. British Journal of Guidance \& Counselling, 32, 223-234. https://doi.org/10.1080/03069880410001692256

Brunner, E. (2016). Drawn from the Classics: Essays on Graphic Adaptations of Literary Works. Studies in the Novel, 48, 255-257. http://doi.org/10.1353/sdn.2016.0016

Byrne, J., \& Kirwan, G. (2019). Relationship-Based Social Work and Electronic Communication Technologies: Anticipation, Adaptation and Achievement. Journal of Social Work Practice, 33, 217-232. https://doi.org/10.1080/02650533.2019.1604499

Caligiuri, P., Baytalskaya, N., \& Lazarova, M. B. (2016). Cultural Humility and Low Ethnocentrism as Facilitators of Expatriate Performance. Journal of Global Mobility, 4, 4-17. https://doi.org/10.1108/JGM-03-2015-0007

Cavallo, A., Ris, M. D., Succop, P., \& Jaskiewicz, J. (2005). Melatonin Treatment of Pediatric Residents for Adaptation to Night Shift Work. Ambulatory Pediatrics, 5, 172-177. https://doi.org/10.1367/A04-124R.1

Chen,Y. P., \& Shaffer, M. (2018). The Influence of Expatriate Spouses' Coping Strategies on Expatriate and Spouse Adjustment. Journal of Global Mobility, 6, 20-39. https://doi.org/10.1108/JGM-07-2016-0032

Devaraj, S., \& Jiang, K. (2019). It's about Time-A Longitudinal Adaptation Model of High-Performance Work Teams. Journal of Applied Psychology, 104, 433-447. https://doi.apa.org/doi/10.1037/apl0000372

Dollard, M. F., Osborne, K., \& Manning, I. (2013). Organization-Environment Adaptation: A Macro-Level Shift in Modeling Work Distress and Morale. Journal of Organizational Behavior, 34, 629-647. https://doi.org/10.1002/job.1821

Durand, M., Vachon, B., Hong, Q. N., Imbeau, D., Benjamin III, C., \& Loisel, P. (2004). The Cross-Cultural Adaptation of the Work Role Functioning Questionnaire in Canadian French. International Journal of Rehabilitation Research, 27, 261-268. https://doi.org/10.1097/00004356-200412000-00002

Faulconbridge, J. R. (2008). Negotiating Cultures of Work in Transnational Law Firms. Journal of Economic Geography, 8, 497-517. https://doi.org/10.1093/jeg/lbn013

Fee, A. (2020). How Host-Country Nationals Manage the Demands of Hosting Expatriates. Journal of Global Mobility, 8, 25-54. https://doi.org/10.1108/JGM-09-2019-0045

Ford, J., Maillet, M., Pouliot, V., Meredith, T., Cavanaugh, A., \& IHACC Research Team (2016). Adaptation and Indigenous Peoples in the United Nations Framework Convention on Climate Change. Climatic Change, 139, 429-443.

https://doi.org/10.1007/s10584-016-1820-0 
Gandhi, S., \& French, B. (2004). Sharing What Works: Adaptation Programmes for Overseas Recruits. Nurse Education in Practice, 4, 114-119. https://doi.org/10.1016/S1471-5953(03)00032-5

Gray-Stanley, J., Muramatsu, N., Heller, T., Hughes, S., Johnson, T. P., \& Ramirez-Valles, J. (2010). Work Stress and Depression among Direct Support Professionals: The Role of Work Support and Locus of Control. Journal of Intellectual Disability Research, 54, 749-761. https://doi.org/10.1111/j.1365-2788.2010.01303.x

Gvozdeva, G., \& Gvozdeva, E. (2006). The Ways of Adaptation and Allocation Work Time from Russian Households in the Period of Crisis. Journal of Comparative Family Studies, 37, 563-582. https://doi.org/10.3138/jcfs.37.4.563

Hack-Polay, D. (2020). Global South Expatriates, Homesickness and Adjustment Approaches. Public Health Reviews, 41, Article No. 11. https://doi.org/10.1186/s40985-020-00122-9

Hair, J. F., Black, W. C., Babin, B. J., \& Anderson, R. E. (2010). Multivariate Data Analysis (7th ed.). Englewood Cliffs, NJ: Prentice Hall.

Harvey, M., \& Novicevic, M. M. (2001). Selecting Expatriates for Increasingly Complex Global Assignments. Career Development International, 6, 69-87. https://doi.org/10.1108/13620430110383357

Jun, S., Gentry, J. W., \& Hyun, Y. J. (2001). Cultural Adaptation of Business Expatriates in the Host Marketplace. Journal of International Business Studies, 32, 369-377. https://doi.org/10.1057/palgrave.jibs.8490958

Kanji, G. K., \& Chopra, P. K. (2009). Psychosocial System for Work Well-Being: On Measuring Work Stress by Causal Pathway. Total Quality Management \& Business EXcellence, 20, 563-580. https://doi.org/10.1080/14783360902875741

Karakaş, A., \& Tezcan, N. Ş. (2019). The Relation between Work Stress, Work-Family Life Conflict and Worker Performance: A Research Study on Hospitality Employees. European Journal of Tourism Research, 21, 102-118.

Khammar, A., Moghimian, M., Ebrahimi, M., Abbasi, M., Baneshi, M., Yari, A. et al. (2017). Effects of Bright Light Shock on Sleepiness and Adaptation among Night Workers of a Hospital in Iran. Annals of Tropical Medicine and Public Health, 10, 595.

Kirkegaard, T., \& Brinkmann, S. (2015). Rewriting Stress: Toward a Cultural Psychology of Collective Stress at Work. Culture \& Psychology, 21, 81-94. https://doi.org/10.1177\%2F1354067X15568978

Kleinschmidt, D. F., \& Jaeger, T. F. (2016). Re-Examining Selective Adaptation: Fatiguing Feature Detectors, or Distributional Learning? Psychonomic Bulletin \& Review, 23, 678691. https://doi.org/10.3758/s13423-015-0943-Z

Lamond, N., Dorrian, J., Burgess, H. J., Holmes, A. L., Roach, G. D, McCulloch, K. et al. (2004). Adaptation of Performance during a Week of Simulated Night Work. Ergonomics, 47, 154-165. https://doi.org/10.1080/00140130310001617930

Levine, K. J., \& Levine, S. L. (2014). Teaching Expatriate Adaptation While Dealing with Reality: The Impact of a Tragedy on the Study-Abroad Experience. Journal of International Students, 4, 342-350. https://doi.org/10.32674/jis.v4i4.453

Linder, C. (2015). Expatriates' Willingness to Adjust Their Symbolic Leadership Abroad. An Analysis of How Culture Affects Expatriates' Use of Symbolic Interaction. Journal of Global Mobility, 3, 244-272. https://doi.org/10.1108/JGM-05-2014-0013

Loring, P. A., Gerlach, S. C., \& Penn, H. J. (2016). “Community Work” in a Climate of Adaptation: Responding to Change in Rural Alaska. Human Ecology, 44, 119-128.

https://doi.org/10.1007/s10745-015-9800-y 
Lu, L., Kao, S., Siu, O., \& Lu, C. (2011). Work Stress, Chinese Work Values, and Work Well-Being in the Greater China. The Journal of Social Psychology, 151, 767-783. https://doi.org/10.1080/00224545.2010.538760

Marcenes, W. S., \& Sheiham, A. (1992). The Relationship between Work Stress and Oral Health Status. Social Science \& Medicine, 35, 1511-1520. https://doi.org/10.1016/0277-9536(92)90054-T

McNulty, Y., Vance, C. M., \& Fisher, K. (2017). Beyond Corporate Expatriation-Global Mobility in the Sports, Religious, Education and Non-Profit Sectors. Journal of Global Mobility, 5, 110-122. https://doi.org/10.1108/JGM-04-2017-0014

Morrow, C. L. (2013). Acknowledgment, Adaptation and Shakespeare in Ron Rash's Serena. South Central Review, 30, 136-161. https://doi.org/10.1353/scr.2013.0011

Murray, S. (2008). Materializing Adaptation Theory: The Adaptation Industry. Literature/Film Quarterly, 36, 4-20.

Nabitz, U., Jansen, P., van der Voet, S., \& van den Brink, W. (2009). Psychosocial Work Conditions and Work Stress in an Innovating Addiction Treatment Centre. Consequences for the EFQM Excellence Model. Total Quality Management \& Business EXcellence, 20, 267-281. https://doi.org/10.1080/14783360902719410

Nilforooshan, P. (2020). From Adaptivity to Adaptation: Examining the Career Construction Model of Adaptation. The Career Development Quarterly, 68, 98-111. https://doi.org/10.1002/cdq.12216

Oltra, V., Bonache, J., \& Brewster, C. (2013). A New Framework for Understanding Inequalities between Expatriates and Host Country Nationals. Journal of Business Ethics, 115, 291-310. https://doi.org/10.1007/s10551-012-1397-0

Orrange, R. M. (2003). The Emerging Mutable Self: Gender Dynamics and Creative Adaptations in Defining Work, Family, and the Future. Social Forces, 82, 1-34. https://doi.org/10.1353/sof.2003.0103

Presbitero, A. (2017). Religious Expatriates' Cultural Intelligence and Adaptation. Journal of Global Mobility, 5, 146-157. https://doi.org/10.1108/JGM-09-2016-0041

Pritchard, S. E., Tse, C. T. F., McDonald, A. C., \& Keir, P. J. (2019). Postural and Muscular Adaptations to Repetitive Simulated Work. Ergonomics, 62, 1214-1226. https://doi.org/10.1080/00140139.2019.1626491

Pullen Sansfaçon, A., Brown, M., Graham, J., \& Dumais Michaud, A. (2014). Adaptation and Acculturation: Experiences of Internationally Educated Social Workers. Journal of International Migration and Integration, 15, 317-330. https://doi.org/10.1007/s12134-013-0288-2

Qin, C., \& Baruch, Y. (2010). The Impact of Cross-cultural Training for Expatriates in a Chinese Firm. Career Development International, 15, 296-318. https://doi.org/10.1108/13620431011053758

Rafiq, A., Saleem, S., Bashir, M., \& Ali, A. (2019). The Paradox Role of Extraversion in the Cross-Cultural Adjustment Process of Asian Expatriates. Psychology Research and Behavior Management, 12, 179-194. https://doi.org/10.2147/PRBM.S191805

Raitt, G. (2012). Lost in Austen: Screen Adaptation in a Post-Feminist World. Literature/Film Quarterly, 40, 127-141.

Robertson, M., Sorensen, C., \& Swan, J. (2001). Survival of the Leanest: Intensive Knowledge Work and Groupware Adaptation. Information Technology \& People, 14, 334-352. https://doi.org/10.1108/09593840110411149

Roniger, L. (2016). Displacement and Testimony: Recent History and the Study of Exile and Post-Exile. International Journal of Politics, Culture, and Society, 29, 111-133. 
https://doi.org/10.1007/s10767-015-9201-7

Rozaimie, A. (2018). Cultural Variations and Socio-Ecocultural Understanding of Cross-Cultural Adaptation. The Qualitative Report, 23, 2538-2551.

Ruddick, N. (2005). Annotations, Appendices, Adaptations: Recent Work on H.G. Wells's Scientific Romances. Science-Fiction Studies, 32, 316-322.

Schieman, S., \& Young, M. (2010). The Demands of Creative Work: Implications for Stress in the Work-Family Interface. Social Science Research, 39, 246-259. https://doi.org/10.1016/j.ssresearch.2009.05.008

Severn, J. R. (2014). All Shook $U p$ and the Unannounced Adaptation: Engaging with Twelfth Night's Unstable Identities. Theatre Journal, 66, 541-557. https://doi.org/10.1353/tj.2014.0115

Shin, S. J., Morgeson, F. P., \& Campion, M. A. (2007). What You Do Depends on Where You Are: Understanding How Domestic and Expatriate Work Requirements Depend upon the Cultural Context. Journal of International Business Studies, 38, 64-83.

https://doi.org/10.1057/palgrave.jibs.8400247

Smith, D., \& Greenfields, M. (2012). Housed Gypsies and Travellers in the UK: Work, Exclusion and Adaptation. Race \& Class, 53, 48-64. https://doi.org/10.1177\%2F0306396811425985

Snowden, K. (2011). Beyond Adaptation: Essays on Radical Transformations of Original Works. Marvels \& Tales, 25, 385-387, 405.

Soumyashree, M., Viveki, R., Kamble, M., Arpitha, V., \& Halki, S. (2018). Effects of Sociodemographic Factors and Work-Related Stress on Work Ability Index among Stone Quarry Workers in a Rural Area: A Cross-Sectional Study. Indian Journal of Community Medicine, 43, 124-125.

Spong, A., \& Kamau, C. (2012). Cross-Cultural Impression Management: A Cultural Knowledge Audit Model. Journal of International Education in Business, 5, 22-36. https://doi.org/10.1108/18363261211261737

Sterle, M. F., Verhofstadt, L. L., Bell, P., \& De Mol, J. (2018). In Search of the Recognition of Expatriate Complexity: Interpretative Phenomenological Analysis of Psychotherapy Experience. The Qualitative Report, 23, 2936-2952.

Strong, J. (2005). Patients' Adaptive Experiences of Returning to Work Following Musculoskeletal Disorders: A Mixed Design Study. Journal of Hand Therapy, 18, 437-446. https://doi.org/10.1197/j.jht.2005.09.008

Tharenou, P. (2013). Self-Initiated Expatriates: An Alternative to Company-Assigned Expatriates? Journal of Global Mobility, 1, 336-356. https://doi.org/10.1108/JGM-02-2013-0008

Thoms, P., Pinto, J. K., Parente, D. H., \& Vanessa, U. D. (2002). Adaptation to SelfManaging Work Teams. Small Group Research, 33, 3-31. https://doi.org/10.1177\%2F104649640203300101

Trembath, J. L. (2016). The Professional Lives of Expatriate Academics. Journal of Global Mobility, 4, 112-130. https://doi.org/10.1108/JGM-04-2015-0012

Vermeulen, K., Woestyn, M., Oostra, K., Geers, S., Ryngaert, K., Van de Velde, K. et al. (2019). Cross-Cultural Adaptation and Psychometric Evaluation of the Dutch Version of the Work Rehabilitation Questionnaire (WORQ-VL). Journal of Occupational Rehabilitation, 29, 514-525. https://doi.org/10.1007/s10926-018-9812-8

Vijayakumar, P. B., \& Cunningham, C. J. L. (2016). Cross-Cultural Adjustment and Expatriation Motives among Indian Expatriates. Journal of Global Mobility, 4, 326-344. https://doi.org/10.1108/JGM-05-2016-0019 
Wang, J. L. (2006). Perceived Work Stress, Imbalance between Work and Family/Personal Lives, and Mental Disorders. Social Psychiatry and Psychiatric Epidemiology, 41, 541-548. https://doi.org/10.1007/s00127-006-0058-y

Wang, J., Chen, C. I., Liu, Y., Barkley, D., \& Wu, C. (2020). Intercultural Competences and Job Satisfaction of Expatriates: The Mediating Effect of Positive Psychological Well-Being. International Journal of Organizational Innovation (Online), 12, 140-155.

Weinberg, A. (2015). A Longitudinal Study of the Impact of Changes in the Job and the Expenses Scandal on UK National Politicians' Experiences of Work, Stress and the Home-Work Interface. Parliamentary Affairs, 68, 248-271.

https://doi.org/10.1093/pa/gst013

Wilson, J., Ward, C., Fetvadjiev, V. H., \& Bethel, A. (2017). Measuring Cultural Competencies: The Development and Validation of a Revised Measure of Sociocultural Adaptation. Journal of Cross-Cultural Psychology, 48, 1475-1506.

https://doi.org/10.1177\%2F0022022117732721

Ziervogel, G. (2019). Building Transformative Capacity for Adaptation Planning and Implementation That Works for the Urban Poor: Insights from South Africa. Ambio, 48, 494-506. https://doi.org/10.1007/s13280-018-1141-9 